\title{
Globalisation of Commodification: Legal Process Outsourcing and Indian Lawyers
}

\author{
Ernesto Noronhaa ${ }^{a}$ Premilla D'Cruz ${ }^{a}$ and Sarosh Kuruvillab \\ arganisational Behaviour, Indian Institute of Management Ahmedabad, India; ${ }^{b}$ Department of Labor \\ Relations, Law and History, ILR School, Cornell University, Ithaca, New York, USA
}

\begin{abstract}
Legal process outsourcing (LPO) refers to the contracting of legal work from regions where it is costly to perform, such as the US to areas where it can be performed at a significantly decreased cost. LPO has been made possible by the disaggregation of the legal processes into discrete units, each of which can then outsourced to cheaper service providers. Anecdotal evidence suggests a variety of benefits such as financial gains, opportunities to perform "global" work in a corporate atmosphere and acquisition of important skills and training that enhances the prestige of the host country lawyers. In India, which has played a significant role, LPO firms are viewed as important catalysts in the transformation of the country's highly stratified legal profession based on social identities. This qualitative study, based on 38 interviews, concludes that the corporate culture was an attractive proposition for lawyers from non-elite backgrounds; however, the commodification of offshored work led to a deprofessionalisation of lawyers, reducing them to "glorified clerks." As a result, LPO firms only provided parallel avenues for career mobility but did not destabilise the local legal market which at its core remains socially networked.
\end{abstract}

\section{ARTICLE HISTORY}

Published online

9 March 2016

\section{KEYWORDS}

Commodification; globalisation; India; lawyers; legal process outsourcing; professions

India has developed a reputation for being the service sector outsourcing capital of the world. It is the world leader in providing a large variety of business process outsourcing services, such as call centres, telemarketing, billing services, tax processing, insurance claims processing and so on. Recently, Indian firms have moved up the outsourcing value chain by providing a number of high skill services, referred to as Knowledge Process Outsourcing (KPO) by the National Association of Software and Services Companies (NASSCOM). These KPOs include a range of services such as market research, medical and life sciences research processes (including clinical trials), data analysis services, business intelligence, financial services research, engineering services research and so forth (Kuruvilla and Ranganathan 2008). The newest service line in these "emerging verticals," is the rapidly growing legal process outsourcing (LPO) industry (NASSCOM 2013). LPO is where in-house legal departments, law firms and other organisations outsource legal work from high-cost regions to places where it can be performed at a significantly decreased cost, primarily India, Chile, Hong Kong, 
Australia, the Philippines and Sri Lanka (see Prasad and Mago 2007). In 2011, LPO firms in India employed more than 10,000 lawyers (NASSCOM 2011). By 2014, LPO contributed about $18 \%$ of the revenue of US\$ 3.7 billion accruing to knowledge services. This is the fastest growing outsourcing sector, expanding by $15 \%$ year on year (NASSCOM 2014).

There are a variety of reasons why India is a preferred destination to offshore legal services, especially for the US and UK markets. First, their shared colonial histories have made the legal systems of the UK, US and India, reasonably similar. Second, Indian court procedures are conducted in English. Third, India produces over 80,000 lawyers annually. Fourth, the time difference between the US and India coheres with modern information and communication technologies and devices (ICTDs) such that American attorneys can benefit from round-the-clock assistance on their projects (Woffinden 2007). And finally, Indian lawyers working on a variety of legal processes cost about a fifth of their counterparts in the US and the UK. These low costs, along with Indian government incentives for starting LPO businesses, are an important reason for the sharp growth of the Indian LPO industry (Fischer 2010; Hanson 2009).

There is a plethora of research on the Indian outsourcing industry. Some authors have focused on India as a model for service sector development, extolling the significant contribution to exports, gross domestic product (GDP) and to employment (see Kuruvilla and Ranganathan 2008). Others have focused on the employment conditions of Indian employees, particularly in call centres, highlighting the Taylorism that partially explains the high turnover rates (see Batt et al. 2005; Noronha and D'Cruz 2009a). The LPO sector, however, has received little academic attention. There is some evidence suggesting that LPO growth has provided previously unemployed or underemployed Indian lawyers with higher pay and better career opportunities. Some have speculated that LPO firms will destablise the highly stratified professional hierarchy in the legal profession, induce specialisation and career growth, thus transforming the profession (Krishnan 2007). Others see limited prospects for such change, arguing that the work done by Indian lawyers is largely routine (Daly and Silver 2007). The strict confidentiality requirements of the American Bar Association requires that LPO employees in India be trained and closely supervised by American lawyers (Bachrach 2008; D’Angelo 2008; Miller 2008; Tuft 2010), raising the possibility that Indian lawyers, like other BPO employees, will be subject to Taylorism.

This article examines the impact of LPO on the Indian lawyers. Specifically, it asks the following questions: What is the nature of the work they do? Do Indian lawyers enjoy their work in their LPOs? Is LPO contributing to their upskilling and the professionalisation? Is it transforming the Indian legal profession?

The article begins by reviewing relevant literature on how the organisation of work in the legal industry is increasingly commodified, and then briefly describes the Indian legal industry. Following that, we introduce our methodology. This is followed by the results of our analysis and our conclusions.

\section{Outsourcing of Legal Services: Towards Commodification}

Through the last two decades, the quest for financial gains has compelled US law firms to disaggregate legal processes into discrete units and outsource each component to the 
most efficient service provider (Regan and Heenan 2010; Susskind 2008). Law firms have been delegating responsibility for discrete tasks such as document review for responsiveness, relevance, significance and privilege; preparation of deposition questions and digests of deposition testimony; briefings with experts; preparation of motions and pleadings; arguments at trial; patent research and application drafting and numerous other tasks to the cheapest person, who could be either a lawyer or a non-lawyer in the supply chain (Harmon 2008; Terry 2008). Thus, a project in total may require the expertise of a lawyer but when broken into component parts it may take on non-legal characteristics devoid of the jurisdictional context (Daly and Silver 2007). Breaking down a project into component parts requires a work flow analysis wherein the steps linked to providing services to an end user are subdivided into constituent sets of tasks and activities, with an estimate of the time and resources needed. Each step serves as the equivalent of a module that can be performed by one set of actors and handed off to others in succeeding phases (Regan and Heenan 2010). Further, advancement in ICTDs allows for a spatial dispersion of these disaggregated tasks to the lowest cost provider down the chain who is invariably an offshore lawyer at a remote location (Terry 2008; Tuft 2010), thus making the practice of law a commodity type of business that drives down the price of legal services (Bierman and Hitt 2007; Brooks 2011; Crain 2004). This process of commodification proletarianises legal work by degrading, deskilling, controlling, intensifying and reducing the technical autonomy of professional work leading to dissatisfaction and insecurity among attorneys as they are absorbed into hierarchical organisations (Brooks 2011).

The offshoring of law, especially from the US to India, represents one further step in the process of the disaggregation of the legal industry. The recent emergence and growth of LPO provides evidence that such decomposition is feasible and requires only minimal firm-specific knowledge (Regan and Heenan 2010; Tuft 2010). The application of six sigma techniques and technology to legal work disintegrates the value chain such that knowledge and information management is dissociated from consultative advice and representation and recast into discrete tasks further routinising practice and intensifying monitoring (Sako 2010; Simon 2012). LPO work, centring around document review and routine support functions, has limited scope, with each task being assigned to the lowest cost provider such as contract lawyers in the US or those situated abroad (Sako 2009). Sophisticated and strategic work such as research, drafting, planning, interpreting, arguing and representing, synonymous with legal profession, is performed by lawyers in the client's country deepening the bifurcation of legal services between the elite and the rank-and-file working in vendor countries (see, for example, Brooks 2011; Regan and Heenan 2010). The elite of client country lawyers retain interesting, challenging and customised tasks that involve a significant exercise of judgement and skill whereas the rank-and-file perform standardised, repetitive, routinised and tedious tasks. Nonetheless, a downside is possible for the client country lawyers too, if routine tasks are used to train junior associates to perform complex legal work in future (Daly and Silver 2007).

Other implications are that as sophisticated tasks are broken down into simpler discrete components, the percentage of work in law firms not requiring complex skills may increase making legal services indistinguishable from other services (Daly and Silver 2007). In fact, there are an increasing number of activities in the legal services 
supply chain being performed by non-lawyers, thus shrinking the territory that lawyers can claim as their own (Regan and Heenan 2010). As a result, some scholars describe lawyers as being just one of the numerous service providers who can regulated as a group creating ambiguity about the skills that distinguish lawyers from other occupations (Harmon 2008; Regan and Heenan 2010; Terry 2008). Indeed, the profession's "noble calling" has given way to the notion of "law as product" less concerned with fiduciary duties and more preoccupied with maximising profits, effectively "deprofessionalising" lawyers (Harmon 2008). LPO is thus an antithesis to the essence of the legal profession.

A further consequence is that law firms have hired increasing numbers of nonlawyers to manage their business including working on financial or strategic planning. However, they have stopped short of employing non-lawyers to oversee project teams in order to avoid a confrontation with lawyers who may resist efforts by a non-lawyer to direct their work (Regan and Heenan 2010). In fact, that the legal profession defines "team" in a closed manner as a group of lawyers and legal service providers, as opposed to a collective made up of lawyers and professionals from non-legal disciplines, evidences that law-related allegiance is privileged over non-legal influences (DeStefano 2012). This is because, despite great heterogeneity and spatial variation, lawyers across the world share a culture of autonomy (Faulconbridge 2008). Supervision is seen as inconsistent with the lawyer's duty to exercise professional judgment (Simon 2012), with the result that legal professionals normally resist being directly managed and value the freedom to independently organise and perform their work without the intermediation of administrators (Faulconbridge and Muzio 2007; Hall 1985).

Examining how the commodification of law through LPO from the US affects the legal profession in India is the focus of this article. Anecdotal evidence suggests a variety of benefits:LPO salaries which far exceed those available to litigators (see, for example, Daly and Silver 2007; Robertson 2011); opportunities to perform "global" work in a corporate atmosphere; and interaction with foreign law firms and clients that enhances the prestige of local LPO lawyers and enables the latter to gain important skills and training. In addition, Indian LPO firms are viewed as important catalysts in the transformation of the country's legal profession, offering the possibility of destabilising the long-standing and highly stratified professional hierarchies based on social identities and social networks that typify the sector (Daly and Silver 2007). Krishnan (2007) suggested that the advent of LPO would also transform the Indian legal profession by helping to introduce specialisation, a feature noticeably lacking among legal professionals. Although most Indian lawyers remain litigators, it is believed that LPO firms would produce experts in an area of law that has an increasing global demand, enabling Indian lawyers to detach themselves from the courts (Moog 2008).

These arguments for imminent social change may be countered. Despite financial benefits and likely reputational gains, Indian lawyers working in LPOs do not receive equivalent opportunities as their American colleagues do. In fact, the outsourcing lawyer's limited interaction with overseas colleagues and clients restricts opportunities for advancement. Further, the work being outsourced does not require nuanced judgment nor does it allow LPO lawyers to build expertise and experience to gain the insights that undergird such judgment. Thus, outsourcing provides avenues at levels 
well below those available to even the most junior lawyer practicing in the US, posing no challenge to the existing social system (Daly and Silver 2007). However, these claims have not been thoroughly verified through research, and this is what we attempt in this article. We next briefly describe the Indian legal profession.

\section{The Legal Profession in India}

The development of the legal profession in the in the US and the UK went hand in hand with the emerging capitalist socio-economic formation. However, this was not the case for India, which inherited the modern legal system as a part of the colonial legacy (Gandhi 2004; Jayaram 1988). The rise of the legal profession both in numbers and in status was an outcome of a range of administrative and legal developments such as the enactment of codes, the founding of High Courts, the right to employ pleaders in civil and criminal suits, the complexity of legal regulations and the increase in litigation (Hegde 1988). Lawyers developed great power, especially after the imposition of stringent educational standards, with some being educated and trained in England (Jayaram 1988; Schmitthener 1968). Later, their involvement with the independence movement boosted their stature (Dezalay and Garth 2004). Not surprisingly, the Indian Constituent Assembly in 1950 was dominated by lawyers with individual lawyers remaining significant in political affairs (Gandhi 2004; Hegde 1988). This link of the legal professionals with the political system through membership and active participation facilitated the durability of the legal systems and institutions that had been imposed by Britain (Hegde 1988).

One of the predicaments of inheriting the British system has been that the contemporary legal system is typified by a mountain of unresolved litigation resulting in a massive delay in providing justice and interminable and wasteful litigation (Galanter 1972; Mendelsohn 2005). In civil cases, losing parties drag proceedings on for years and decades. Thus, a subcategory of "delay lawyers" who are specialists in perpetuating the length of litigation have emerged (Krishnan 2007). However, despite lawyers and judges agreeing that the system displays serious defects such as perjury, delay and proliferation of appeals, the bar on behalf of vested interests, has resisted reforms considered deleterious to those interests (Galanter 1972; Moog 2008).

Legal work has been concentrated in a small section of senior lawyers, while the vast majority make do with only a small proportion of the business and depend on touts to get clients (Jayaram 1988). This inequality is reinforced by the exploitative apprenticeship system that exists between senior and junior lawyers (Krishnan 2010). Moreover, this system of tutelage is accessible only on the recommendation of friends, relations and acquaintances (Sathe et al. 1983). Strong family connections with practicing lawyers smoothens the career prospects (Dezalay and Garth 2004). Without regard for merit, sons and daughters follow their fathers into many of the firms to become partners later. Even well-trained lawyers have little chance to succeed at the bar, without the help of a practising family member or relative (Mendelsohn 2005).

The poor quality of legal education did not help. The proliferation of law colleges after independence did not improve the quality of legal education and standards of teaching vary from indifferent to deplorable (Ballakrishnen 2009; Gandhi 2004). The limited rigour of training in these schools and easy credentialing of the profession 
make law the most accessible 'professional' degree that a student can acquire (Ballakrishnen 2009). As a result, overcrowding and unemployment at the bar results in the emergence of the "briefless barristers" and unprofessional practices such as touting, overcharging and professional rivalry (D'Allaird 2007; Schmitthener 1968). With professional bodies exercising a negligible control over the behaviour of lawyers, these malpractices are accentuated. The popular perception is that the legal profession is exploitative and populated by unscrupulous promoters of litigation is not unfounded. Indeed, Indian lawyers have been oriented towards litigation rather than in advising, negotiating or planning (Moog 2008). In sum, the Indian legal profession is plagued by multiple issues such as being primarily geared towards litigation, delays, exploitation of clients, poor quality education, overcrowding and stratification based on family ties.

\section{Methodology}

Given this context, our study seeks to understand the work experiences of lawyers in LPO firms using inductive and qualitative methods, which better allow us to interpret how employees view their work. Data were gathered through in-depth, unstructured, open-ended, face-to-face conversations between the researchers and the participants. Participants had the option of signing a consent form, informing them of details about the study and their rights as participants (namely, informed consent, voluntary participation and confidentiality). The location of the interview was decided by the participant who also had the freedom to decide whether the interviews could be recorded. None of the participants objected to this. Audiorecorded interviews were transcribed verbatim and observations made during the interviews were recorded.

Participants were selected by snowball sampling. As accessing to LPO firms was difficult, we do not make any claims to representativeness of our data. Our interviews were done in two phases. The first phase covered 21 employees working in LPOs in Bengaluru (formerly Bangalore). Of these 21, three were CEOs (one was Canadian), two Chief Operating Officers (COOs), six managers (two were American), two team leaders and the rest were senior and junior associates. All but two had prior litigation experience. On learning from our Bangalore interviews that LPO firms in New Delhi were more likely to be engaged in higher quality legal work, we embarked on Phase 2, interviewing 17 participants in New Delhi. These included one general counsel to a LPO, one legal consultant to LPO firms, five lawyers employed as managers in LPOs and ten junior and senior associates. Of our sample of 38 employees, 16 lawyers had prior litigation experience in India. This was an important consideration, given that Indian lawyers in LPOs are not supposed to engage in litigation anymore, and we wondered how the transition from litigation to legal support in LPOs would be seen by these participants. ${ }^{1}$

Two major themes emerged from the data analysis. The first, captures the efforts of LPO firms to ensure organisational functioning and develop a workplace culture in ways which appeals to both clients and employees. The second major theme relates to the experiences of the work itself, the skills and professional identity of Indian lawyers. We expand on these themes below. Together, the major themes and 
sub-themes point out how offshoring of legal work, impacts the Indian lawyers working in LPOs.

\section{The Temptations of a LPO: Creating and Sustaining an Image}

LPO firms try to build an image and organisational culture that maximises both client and employee satisfaction, while being regulated by service level agreements (SLAs) signed between LPO and client firms that have highly specific performance parameters. These SLAs keep the client satisfied, through quantitative and qualitative parameters regarding accuracy, workload targets, six sigma, data security and ethical standards. At the same time, LPO management attempts to increase employee satisfaction via Western management practices that privilege rationality, objectivity, transparency, performance, merit, equality and inclusivity. This contrasts with the Indian legal workplace ethos where hierarchy, seniority, social categories and networks, ascriptive status, personalised and identity-based relationships, ingratiation and sycophancy have prevailed. Three sub-themes are relevant here: the construction of a client-focused organisation; the lure of corporate culture; and gains from an alternative career.

\section{Constructing a Client-Focused Organisation}

Offshoring to India builds on the pre-existing practices of outsourcing. US law firms have long relied on domestic vendors to provide necessary services and offshoring is a spatial extension of this. Yet, as offshoring involves lawyers overseas who are not licensed in the US, ethical issues warrant attention. A predominant concern surrounding offshoring is the inability of US law firms to enforce confidentiality, especially when foreign lawyers undertake legal work or when two firms representing opposing sides in a case use the same LPO firm. To address these issues, US bar associations insist that American lawyers must supervise foreign LPO lawyers, review the final product, protect against any breach of confidentiality and confirm the absence of any conflict of interest.

These ethical issues required vendors to build an image of a client-savvy organisation both in terms of trustworthiness and effectiveness in delivery since US law firms were advised to investigate the background of every prospective LPO service provider (see D'Angelo 2008). Law firms had to ensure that the overseas vendor had a solid reputation and were familiar with issues related to American professional responsibility and legal participants. As far as possible, only overseas companies that had a US office and employed US-licensed attorneys or managers were to be contracted. Thus, Indian vendors were sensitive to the US bar associations' mandate requiring US lawyers to supervise foreign LPO lawyers. As a result, some LPO vendors set up offices and employed lawyers in the US to persuade law firms to outsource to India, as a COO of an LPO firm affirmed:

Everybody thought that like the IT and BPO industry you first set up LPO shops in India, get work here and expand it big scale ... without any operational presence onsite. That just didn't work. Because when we set up in 2006-07 and we talked to lot of partners they said, "we are just not ready because we don't understand this market. However, if you guys have some kind of US operations, over a period of time we will work with you, get comfortable and will think about it sooner or later." (Interview, December 23, 2009, Bengaluru) 
LPO vendors also prodded clients to outsource by suggesting strategies that benefit the latter. One approach was the staged contractual commitment whereby firms initially outsource only small amounts of work for brief durations. However, with time and as vendors demonstrate trustworthiness, the length of the contract and its complexity increases. The other approach was to contract multiple suppliers and benchmark performance to achieve cost savings. Our participants indicated clients' use of a mix of both these strategies.

Before any big project, clients implement pilot projects with four or five vendors whose performance is evaluated and compared. On the basis of this performance clients select one vendor to implement the project. (Interview, Indian Lawyer and Senior associate, January 28, 2011, Bengaluru)

In the first project the client wanted to see the resumes and interact with employees deputed to work on the project. They therefore visited our office for a week before the project started. As the comfort level increased, in the second project, they just wanted to know the employees who would be working on the project. (Interview, Indian COO and Lawyer, January 28, 2011, Bengaluru)

Besides exercising caution while transferring a project, SLAs defined every parameter of the client-vendor relationship including the work to be done, billable items or units, deliverables, productivity and quality benchmarks, reporting requirements, project management methodology, pricing and terms for payment and adjustments. Emanating from these SLAs were service-level matrices that were used to evaluate the performance of employees. Targets were generally decided by clients (based on estimations that were adjusted upwards or downwards during the course of the project), which then trickled down on an hourly basis to individual lawyers. In spite of having well-defined SLAs the decomposing of legal services into discrete parts required constant communication and co-ordination between clients and implementers. Accordingly, project managers interacted with the clients to understand their needs, determine the nature of the work and estimate the required task time. Close interaction ensured that the vendor's lawyers meet expectations and any errors could be corrected early in the project by an attorney at the client site thereby reducing the losses. To this end, LPO firms also recruited US lawyers and based them in India for the posts of project managers and above. These personnel supervised and reviewed the work of Indian lawyers at the associate level before the product was sent to clients, as noted by one of the interviewees:

Employing foreign lawyers to supervise is comforting for some clients, especially those outsourcing for the first time. It's not like because I am from the US, I am doing a better job than the Indian Project Manager .... but the issue is of comfort. For a client India might as well be another planet. They want somebody that they can have a phone conversation with someone with the same accent who is going to understand everything that they say, who is going to be able to put them at ease, and be the face for the company. It's like, "okay I am sending this work 8,000 miles away there has to be one person there that I know I can have some sort of understanding and a comfortable conversation with." (Interview, American, Lawyer and project manager, January 30, 2011, Bengaluru)

To counter pre-existing prejudices and to meet ethical standards, we found that LPO firms employed only trained lawyers holding a Bachelor of Law degree, even though a large proportion of LPO tasks could be executed by non-lawyers, paralegals or 
graduates with good English and numerical skills. Further, LPO firms such as QuisLex, Bodhi Global Services, and the Clutch Group used the specially designed Global Legal Professional (GLP) examination to screen LPO job candidates. ${ }^{2}$ The GLP tested prospective applicants in English fluency, technology, professional skills, personal effectiveness and legal knowledge. After the written examination; LPOs conduct 3-5 rounds of screening interviews. Some firms adhere to stringent standards of interviewing $10 \%$ of all applicants and selecting only $20 \%$ of those interviewed. Following this initial screening, a dossier including the resume and certificates of the prospective employees is sent for clients' approval. While some clients complete their own background checks, others go by the information in the dossier. Once the new recruits are finalised, processrelated training is conducted generally by US lawyers who seek to replicate their own law firms' processes and ethical practices at the vendor's premises.

As noted above, confidentiality is a key issue. A senior associate Indian lawyer, stated: "Security and confidentiality are very important. After office hours, we are not supposed to disclose the client name and once the project manager leaves for the day, you cannot continue to work in office" (Interview, January 30, 2009, Bengaluru). Related, LPO vendors assure US-based attorneys that they keep complete control on the data and/or on customer accounts by retaining all the original files and documents, with duplicates being sent to LPO firms. LPO employees compulsorily sign nondisclosure agreements with clients and rules regarding disclosure to a third party including colleagues, friends or family without prior consent of the client. Employees are also required to abide by the laws, policies, regulations and rules of the clients' country. Data safeguard norms prohibit unauthorised access to the server room, restricted internet access, ban mobile phones, writing devices, sharing of individual PC files and folders or attaching any Bluetooth, infrared, data storage devices to office computers. Paper shredders are used, the network is secured, storage encrypted, advanced data backup and recovery systems provided, cameras installed for surveillance and regular security checks performed on employees and visitors to avoid any data leakage, in addition to security guards being present at all LPO firms.

\section{The Lure of Corporate Culture}

While the above safeguards kept the client satisfied, LPO firms also had to focus on attracting "talent" in India. One method was to adopt an American-oriented professional work culture, reflecting their clients' ethos, endorsing objectivity and transparency as well as diversity and equality by eliminating biases in recruitment, training, evaluation and promotion. Although this approach was sometimes little more than rhetoric, it did appeal to LPO lawyers as new firms allowed the lawyers to side-step family-run practices. They could escape the humiliation of subordinating themselves to established social networks and the inequality reinforced by the exploitative apprenticeship system. Not surprisingly, lawyers were impressed that LPO management attempted to make their organisations fully inclusive and accessible to employees of both genders from across the country belonging to multiple castes and religions. Superior performance was rewarded by adequate compensation and promotion through internal job postings, with awards for those who performed well, as indicated by the following response: 
The opportunity for [professional] growth in an LPO is relatively higher than in law firms. In law firms, if a Minister's son comes with a reference, or a judge's sibling or son or whoever comes with a reference, that person is going to be selected over you. He will be taken no matter whether the gentleman knows his work or not. He will be given the opportunity to work on high profile cases. Whereas in LPO firms the team manager knows what each and every one is doing and you get recognised for it. (Interview, Indian Lawyer and Corporate manager, December 21, 2009, Bengaluru)

Using "coveted" designations such as legal executive, legal assistant, associate attorney and legal associate, LPO firms espouse embrace a friendly and non-bureaucratic environment fostering open communication irrespective of age, gender, title or tenure. This is in sharp contrast to the hierarchical nature of business relationships in India. The LPO firms also ensured that their recruits were malleable to American organisational culture. Some firms resisted recruiting older employees, considering they would find it difficult to adjust to the LPO practice where younger employees supervise elderly subordinates. In the case of those having litigation experience, "cultural fit" such as adjusting to a non-hierarchical structure was the most important criteria for selection. Prior work experience was seen as making people less receptive to instructions as it was difficult for lawyers to unlearn skills, values and processes. Consequently, recent law school graduates were preferred, as they could be moulded to the LPO's corporate culture.

Finally, LPOs provide world-class infrastructure and high quality working conditions with air-conditioned offices and benefits such as complimentary food, beverages, health allowances, medical insurance, recreational facilities, transport for employees and meditation rooms. Firms also appoint engagement managers to organise cultural and social functions such as family days, team lunches, cultural weeks, competitions, random walks, outings, celebrations, and more. Some argue that such benefits restore the prestige of the legal profession. Undoubtedly, LPOs create exciting images around which employees could construct their workplace identities:

LPO give the impression of being a part of a MNC having plush offices that resemble software companies. As a result, lot of employees are enamoured. Moreover, those who join are mostly 22 year old freshers who get about Rs 18,000 per month; they are very happy. When I started at 21, I got Rs. 500 per month but it is very different today. (Interview, Indian Lawyer and Senior Associate, November 16, 2011, Delhi)

\section{Gains from an Alternative Career}

We found that LPOs employed those who did not graduate from the top law schools, those who had drifted into the profession by accident or as a refuge against unemployment and those who detested litigation that required lawyers to haunt courts with no guarantee of success even after several years of investment in practice and infrastructure. These lawyers liked LPO jobs owing to their systematic, well-planned and organised nature and assured growth. After about two years of experience, LPO employees were eligible for promotions to senior legal executive, senior legal associate, team leader (TL) and assistant TL, based on their performance at the entry level. Further, promotions to middle and senior management came after three to seven years of LPO experience. Apart from these prospects, LPO lawyers enjoyed supervisory opportunities 
early in their careers. LPOs provided an early possibility of becoming a manager with a stable income and meaningful progress whose jobs involved driving targets, mentoring individuals and teams and resolving employees' concerns. As one American lawyer working in India stated:

I feel like I have more autonomy. I report directly to the COO and there isn't any other American lawyer in the office. So you know I have been given a lot more responsibility in terms of deciding how to execute projects, judge performances.... This isn't what I thought I was going to be doing over here. I thought I would have somebody knowing all of that and just having me execute it. (Interview, American Lawyer and Project Manager, January 30, 2011, Bengaluru)

Given these circumstances, some lawyers directly joined LPOs foregoing their Bar Council license, while being aware that over a long period of time the earnings were likely to be higher in litigation as compared to LPO employment. As one lawyer noted:

In the legal fraternity it takes 10 to 12 years to establish your name. If you have no background it takes longer than that.... In an LPO, if I move from the base level to a Quality Analyst, from Quality Analyst to a Team Lead, Team Leader to a Team Manager, the jump is constant.... LPOs offer great career path. I know lawyers with five to seven years of experience managing 20 clients and a team of 50 to 60 lawyers. (Interview, Indian Manager and Lawyer, May 5, 2012, Delhi)

Our participants often contrasted their experiences in LPOs with those in litigation, arguing that as individual practitioners they could only operate autonomously once they themselves became senior lawyers. Besides this, litigation was precarious employment with the vast majority depending on touts to get clients or on unprofessional practices such as overcharging. Alleging that the whole system was corrupt, many women preferred to join LPOs. They did not fancy the idea of trying to establish themselves in a male-dominated profession and then being labelled "morally corrupt" in a society where working, middle-class women challenge gender stereotypes. For young women lawyers who were single parents, LPO firms provided them with an option to make a decent living. As one explained:

I feel more secure in an organisation where the timing of work is fixed, and you are not exposed to unwanted elements from outside. If I take up a criminal case, I will be dealing with a drunkard, robber, or a murderer. Though I am not comfortable with these interactions there are women who do the job. I prefer to spend time with my family. (Interview, Indian Lawyer and TL, January 5, 2010, Bengaluru)

In addition, LPO firms provided alternatives to those aspiring for a better quality of life and higher and regular remuneration. Indeed, early career lawyers underscored that LPO salaries were 4-5 times higher compared to those in litigation. One Indian Lawyer, an Associate, stated: "I practised for about eight months earning Rs 1,000 per month as a lawyer while I get about Rs 250,000 per annum as cost to company with a take home of about Rs 28,000 in the LPO firm." (Interview, January 3, 2010, Bengaluru)

Lawyers with litigation experience alluded to the possibility of work-life balance in LPO employment. Fixed hours, five day work weeks with eight hour shifts and no work to be carried home were mentioned. Informants compared this with practitioners working for law firms or as independent litigators who faced late working hours, often with no weekends or holidays, as they pursued partnership credentials. One 
informant stated: "I decided I don't want to give away my present for my future. My future may not be very bright, but it would not be bad if I continue with a LPO firm. I want a stable life...” (Interview, Indian Lawyer and Corporate Manager, December 21, 2009, Bengaluru).

Interestingly, the benefits of LPO employment were not limited to Indian lawyers. American lawyers who had worked as temporary or contract lawyers in the US found secure, fulltime and better quality jobs in Indian LPO firms, reporting professional enrichment and financial, material and affective gains. These expatriates felt greater job satisfaction and led more lavish lifestyles than what they enjoyed back home (see also Robertson 2011).

Global exposure through multinational in-house counsels or law firms constituted another benefit of LPO employment. The familiarity with the US legal system opened up opportunities for those joining the corporate sector as non-prestigious transactional work done for MNC clients gained value. Being endowed with managerial skills on account of their LPO jobs improved lawyers' career job mobility in the broader BPO industry.

From this discussion it can be concluded that the ethical issues surrounding LPOs required vendors to address issues related to confidentiality and unauthorised practice of law, even though the responsibility lay with their American clients. Vendors in India acquiesced to client demands, readily signing SLAs specifying numerous process-related requirements, job design and evaluation parameters for their lawyers. US-trained lawyers recruited to work from India supervised and reviewed the work of Indian lawyers before the product was sent to clients. Besides this, to counter clients' proclivity of blaming their Indian colleagues for errors, LPO firms employed only trained, degreeholding lawyers.

In order to attract high quality employees, LPOs offered Indian lawyers salaries which far exceeded local pay scales, opportunities to perform "global" work in a corporate atmosphere and an opportunity to detach themselves from the local courts (see Moog 2008; Robertson 2011). In contrast, temporary lawyers doing similar work in the US worked in poor physical conditions such as warehouses, basements and even condemned offices (Brooks 2011).

As observed elsewhere, LPOs emerging as a response to the external stimulus of globalisation, embodied international processes and standards that allowed for the sidestepping of preceding small-scale and family-run practices (Ballakrishnan 2013). The objectivity and transparency as well as diversity and equality aimed at eliminating biases in recruitment, training, evaluation and promotion espoused by LPO was in sharp contrast to the hierarchical nature of business relationships in India.

\section{The Roots of Disenchantment}

The second key theme that emerged from our fieldwork was the host of challenges that LPO employees confronted. While LPOs provided lawyers with attractive returns, a corporate work environment and an alternative career path, the commodification of tasks and the institutionalisation of controls, linked to the imperatives of global offshoring and facilitated by technology, limited their job complexity, autonomy and variety, resulting in deskilling and deprofessionalisation, accentuated by restricted client 
interaction. The themes discussed below paint a picture of persistent skill deficits, striving for control, limited client access and experiencing disillusionment.

\section{Persistent Skill Deficits}

Legal work is considered a craft with elements of complexity, autonomy and variety such that task performance is customised to the needs of each client (Sako 2010; Spar 1997). In contrast, LPO work centring around document review and routine support functions, has limited scope. A time intensive but mundane task, document review lends itself to division, standardisation, routinisation, objectification and measurement, allowing for the application of process-driven measures such as accuracy, efficiency and cost-effectiveness. Originally assigned to US contract attorneys, this high volume and scalable work is the safest and most appropriate task to be outsourced. Its simple features call for minimal supervision and present low legal and ethical risks, whereas its systematised nature precludes collaboration such that it can be performed at remote sites by several reviewers simultaneously with each one adhering to the parameters provided by the clients in the service-level agreements (SLA). As a lawyer told us:

Any ... scalable business has to be to a certain extent process oriented. You can't have a very complicated process which cannot be replicated, which cannot be trained. When it comes to a process which is repeatable and replicable, then it has to follow standard protocol.... Research gets quite complicated in terms of understanding the nuances of it; it's quite judgmental and subjective, it's not number driven or scalable. (Interview, Indian COO and Lawyer, January 28, 2011, Bengaluru)

The commodification of the legal value chain has numerous implications for the nature of work LPO lawyers undertake. Participants underscored that being low on complexity, variety and autonomy, LPO work embodies routinisation, standardisation and intensification, meaning that repetition and monotony prevail. The predominance of mechanistic tasks, the demands of highly specialised US clients, the reliance on a restricted range of foreign clients, the disaggregation of legal work, the limits placed on LPOs to provide legal advice and the limited capacity for better quality, more interesting and engaging work underlie the situation. LPO work is clerical and paralegal, with participants describing it as "a-copy-and-paste-job" designed for people with generic skills and average intelligence who do not need to execute discretion. Rather than knowledge of law, even undergraduates familiar with e-discovery software and with a command of English could perform with speed and accuracy. Trained legal professionals found LPO work inconsistent with their traditional job portfolios. Instead of meaningful, challenging and socially useful work driven by autonomy and performed in collegial contexts with significant client interaction, LPO lawyers are deprived of task identity and significance and have little control over work conditions, pace or content. Tedious, regimented and unrewarding jobs split off from the larger case are the norm. Participants stated that they had to blindly follow client instructions, with any change in work processes requiring client approval. One stated:

We don't have any legal input, any strategic input on how matters should be handled. Here we are at the receiving end; it's the client telling us what to do. There is not much 
autonomy, we just execute ... what we are told to.... Even as an associate in a law firm you have a lot more inputs in the process. (Interview, American Lawyer and Vice-President, December 27, 2009, Bengaluru)

Our findings underscore that deskilling and deprofessionalisation is the experience of LPO lawyers. Yet, LPOs purposively sought to employ lawyers as they strove to meet client requirements and perpetuate business interests. The requirement for employing lawyers did not take the job out of the paralegal realm. As a consequence, some LPO lawyers considered themselves "glorified clerks." Not surprisingly, LPO firms disclaim that they provide legal services, they only compiled and synthesised information that lawyers used in providing legal services and had no lawyer-client relationship in the traditional sense: "We are not a law firm which means we are not necessarily qualified lawyers and we are not necessarily paralegals, we are a legal outsourcing company. The client needs to be satisfied that we can produce legal content that's adequate and appropriate" (Interview, Canadian Lawyer and CEO, January 31, 2011, Bengaluru).

Deskilling and deprofessionalisation meant that LPOs cannot attract "the best and the brightest" lawyers in India despite the contrary view being widely propagated by some commentators (see Schultz 2010; Robertson 2011). Although vendors claimed that each of their lawyers graduated from one of the top five or ten law schools, had practised law for at least three years, received extensive legal training from US attorneys, had significant contract experience at a top Indian law firm or corporation and had passed a rigorous legal research and writing exam (see Krishnan 2007), our findings suggest that hiring competent lawyers in the LPO industry is a challenge. None of our participants working at the associate levels were from the premier law schools. Although a few elite law school graduates joined LPOs at senior levels, most preferred the traditional legal jobs of becoming partners in law firms or counsels to corporate houses. The notion that the LPO industry was the administrative back office for US attorneys or another BPO firm in the legal field further dented the possibility of recruiting the best lawyers. This was acknowledged by a CEO of an LPO.

I mean the NLS [National Law School] graduates are typically not ideal candidates [for an LPO].... Right now the pay scale for NLS graduates joining top law firms or large legal departments of Fortune 500 companies or large Indian companies is higher then what LPO firms will offer. Further, I think there is also a perception that the work is not as challenging as they would get in large law firms or legal departments so they are not typically the candidates that will apply for a position in LPOs. Those applying are from tiers below the NLS. (Interview, Canadian Lawyer, January 31, 2011, Bengaluru)

A Vice-President of an LPO added to the comparison between LPOs and law firms:

Arguing in front of the court, developing those arguments and legal skills...We don't do any of that here. Basically, it's very limited; it's not really legal work. So its different types of skill sets that I am developing now, it's more corporate skill sets.... I do a lot more quantitative stuff working with Excel. I had never seen Excel while I was practicing ... in the US. But I am not growing as a lawyer, and these people who are very junior lawyers [for LPOs] are not really growing as attorneys either. The growth in the organisation has nothing to do with legal stuff. It's really learning how to be a manager and learning what happens in a corporation. What I miss here is some intellectual challenge that comes with working in law firms. Some intellectual satisfaction [by developing] ... great arguments or [that] I convinced the judge of something that I didn't think he would [accept].... So [I 
miss] a lot of satisfaction that comes from that; I don't really get here. (Interview, American Lawyer and Vice-President, December 27, 2009, Bengaluru)

Thus, those with experience of litigation find it difficult to make adjustments with LPOs. In hindsight, they also rue their decision to join LPOs because it meant sacrificing one's skill, autonomy and professional identity for short term goals. In the Indian context, as Schmitthener (1968) notes, for litigators besides making a good living, the prestige, promotion and honour shown to successful members of the profession were important. As one informant explained:

I felt very liberated as a litigator; you can even go to the court and tell the judge, "you are wrong."... This is not possible in in a corporate world.... In spite of all the odd working hours and not being paid overtime, litigation is still preferred. The kind of money you make in litigation is different. It is not a salary... . Litigators make huge money. But finding your own place would take time. (Interview, Indian Lawyer and Project Manager, December 28, 2009, Bengaluru)

\section{Striving for Control}

Challenges to lawyers' cherished requirement of discretion, which emerged with the growth of in-house counsels in relation to corporate law are magnified in LPOs. LPOs, being part of global production networks, require interdisciplinary managerial systems to ensure optimal service delivery for clients. Under these circumstances, where nonlawyers oversee operations and are responsible for process-linked targets, deadlines and quality, the possibility of conflict with lawyers remains high. Non-lawyers' attention is centred on client-customised mass production generally within the scope of six sigma techniques, whereas lawyers, seeking to maintain the specialised quality of their task, insist that the knowledge and skills of legal work necessitate autonomy. In their view, supervisory non-lawyers, lacking legal expertise, are unable to comprehend the legal dimensions of the process and hence circumscribe independent functioning. Lawyers dealt with this not just by ignoring their managers on grounds they lacked competence but also considered their real superiors to be their legal counterparts in the US. Participants further asserted that since LPO work was knowledge-based it cannot be cast as BPO work, which was seen as an inferior job, thus bringing in personnel from the BPO industry to manage LPOs was insulting, inappropriate and incorrect. As one Indian lawyer stated:

If you have ten managers, there may be only two lawyers amongst them, that too, at the project manager level ... all the rest are non-lawyer managers. From CEO to VP ... even the TLs are just graduates and not lawyers while associate and senior associates are lawyers.... Operating a call centre is different to operating an LPO; those who manage should have proper knowledge of law. (Interview, January 4, 2010, Bengaluru)

Yet, the mandate of LPO necessitates managerialism. As pointed out by LPO vendors, since job design and work organisation tied in with client expectations, document review lent itself to and called for managerial controls rather than responsible autonomy or manufactured consent, as Brooks (2011) observed for the US. An Indian lawyer, working as a Project Manager, stated: 
The kind of work you are supposed to do in document review has nothing to do with your understanding of law. You work ... [strictly to] the guidelines.... A lawyer with five to eight years of experience will always try to apply his mind to the work sent by the clients, whereas, for most LPO work this is not required.... The client may not appreciate tinkering with the specifications even though you know it is ... the best way. You may send an email saying kindly guide, kindly suggest and wait for the client's answer. (January 3, 2010, Bengaluru)

Indeed, given the simple nature of the tasks, non-legal personnel could easily direct operations regardless of the industries, legal issues and law firms involved. Processlinked targets, time and precision comprise the main dimensions. Supervisors constantly monitored the team to count the number of documents and hours worked, keeping in mind that there was a stringent accuracy level to be achieved and a strict time period within which employees must finish work (work completed beyond the stipulated time was not compensated). The need for quality and quantity was constantly emphasised in employer-employee interactions. In addition to having to compete with each other and establish competence through a test to secure a position on every new project, employees had to meet targets while ensuring zero error rates, intensifying work-related pressure. Work volumes had to be managed without the payment of overtime in spite of the provisions of the Shops and Establishment Act. Forfeiting breaks owing to heavy inflows, with absenteeism being addressed through work redistribution among team members rather than through the creation of buffers, was common. Apart from citing instances of the closure of LPOs for substandard services, daily and weekly feedback was provided in a bid to guarantee performance. Intra-team comparisons were used to ensure that individual employees did not impede the group, with stragglers counselled or put on performance improvement plans. In the latter, time frames were laid down to capture employees' improvement and mentors were assigned to provide the necessary motivation and guidance. If poor performance persisted, the manager escalated the issue to the Human Resources department for additional training or alternative placement. If performance still did not improve, dismissal followed. Employees who repeatedly failed screening tests for new projects were also asked to resign.

Participants' narratives evidenced that lawyers' work experiences moved from a focus on professional relationships, built on trust and independence, to encounters rooted in efficiency. Although the focus on profit maximisation and employee exploitation through work intensification was constantly referred to, it was the denial of professional respect through managerialism that hurt lawyers' pride. For those with litigation experience and autonomy, performance management was a cultural shock. With lawyers trained to have self-belief and conviction in their arguments, the perennial scrutiny and monitoring in LPOs was unnerving. Not only were conflicts with non-lawyer managers rampant but lawyers with supervisory roles experienced heightened discomfort linked to the performance management system and the "unpalatable" task of giving or receiving feedback.

LPO firms pursued the resolution of hostilities between lawyers and non-lawyers through the bifurcation of organisational functions into core operations and support services integral to process delivery. Whereas lawyers were entrusted with operations that necessitated engagement of legal knowledge, non-lawyers had charge of the 
support aspects that undergirded core functions and ensured organisational success. Thus, while the CEO and COO in LPOs were non-lawyers and hence neither interfered with daily operations nor interacted routinely with lawyers, HR tasks were also assigned to specialists since lawyers had no experience of organisational culture and personnel management. This trend reflected similar experience in law firms that hired nonlawyers to oversee the business of the firm, whereas project management was delegated to the lawyers (DeStefano 2012). Thus, unlike the partnership model of conventional law firms, LPOs followed a corporate organisational design that emphasised the Managed Professional Business (MPB) framework where the logic of individual autonomy and collegial control is replaced with a greater reliance on hierarchical authority (Scott 2008). ${ }^{3}$

The efficacy of MPB structures was circumscribed when non-lawyers bid aggressively for projects and over-committed deliverables to clients. To rectify this, some organisations attempted to build a symbiotic relationship between lawyers and non-lawyers. Non-lawyers prepared proposals for prospective projects and had these vetted by lawyers before progressing discussions with clients. Notwithstanding the ensuing cooperation, the gap between lawyers and non-lawyers remained difficult to fully bridge. On the one hand, lawyers' lack of business skills necessitated reliance on managerial experts in the interests of competitive advantage. On the other hand, the influence of non-lawyers in the legal field, albeit as managers, perpetuated the migration of only low-end commoditised legal work such as document review to offshore destinations. Interviewees opined that the optimal answer to this impasse lay in equipping lawyers with business skills; having legal and managerial abilities was the most appropriate means to LPO success.

Managerialism in LPOs was not limited to firm functioning but often included clients directly or indirectly. In the former instance, LPOs provided clients with updates, sometimes in real time, about individual employees' performance, allowing them to check the work of each team member. When clients returned work because of poor quality or mistakes, not only was the salary of the poor performer deducted but he/she had to redo the task without extra pay. In the latter instance, LPOs committed and delivered above clients' specifications in order to impress clients, a common practice observed in Indian offshoring (D'Cruz and Noronha 2012). In line with this, LPOs mostly succumbed to client pressure and delivered on schedule even when delays arose owing to client confusion. Participants' accounts cohered with the notion that client service was a rhetorical trope to conceal control mechanisms (see Campbell and Charlesworth 2012). One Indian lawyer and CEO explained: "At times the client ... needs the work done in a certain time, [so] we need to mobilise our resources and plan accordingly. [For] ... a big project I typically give a buffer of a week or two, I never tell the team working [on the project] what the actual deadline is" (Interview, January 28, 2011, Bengaluru).

American lawyers working in India highlighted that the tracking of performance of contract lawyers in the US was not as stringent as observed in Indian LPOs. Simon (2012) reports that America-based outsourced work was never seen as an assembly line, even where six sigma principles, matrices, error rates and Excel were used, ostensibly because the quality management methodology standardising work there was limited. In Indian LPO firms, however, it was not unusual to introduce a second level of quality 
checking completed by the Director of Operations (a licensed attorney based in the US) prior to client delivery. An American, Lawyer working as a Project Manager explained that Indian firms:

... get pretty detailed feedback for every task or project they are on.... US law firms do not track speed, they weren't checking productivity, they weren't really checking error rate.... But here it is as if you were producing something on a conveyer belt. The COO of the LPO, who is a six sigma black belt, implemented all these processes and measures in order to make the process product-oriented to please the customers. This was an eye opener for me because I had not thought of this work being like an assembly line, like a tangible good or something that could be subjected to quality inspection. So that was pretty hard. (Interview, January 30, 2011, Bengaluru)

\section{Limited Client Access}

Direct consultant-client interface is a hallmark of professional service firms, serving as the facilitator of customising services to suit expected requirements (Segal-Horn and Dean 2007). Lawyers are no exception, considering client interaction, including understanding specific needs and providing appropriate solutions through the engagement of their knowledge and skills to match the complexity of the job, to be their primary professional activity. Not only do clients approach solo practitioners or law firms for their services (with even junior lawyers dealing directly with clients) but a long-term relationship with repeated interaction is often common. LPOs alter this, replacing human interaction with ICTDs thereby depriving LPO lawyers of a personalised client relationship. The commodification of LPO work negates the significance of direct client contact, generally limiting these relationships to supervisors and managers. This has two implications. First, although lawyers involved in process delivery on the operations floor could either listen in to these conversations or receive briefs from their superiors, the decomposition of legal services into discrete tasks impedes the task execution owing to indirect communication. Nonetheless, supervisors and managers privy to client access must perform a linkage role, appraising their subordinates of client specifications to ensure seamless and optimal service provision. Second, lawyers at lower levels remained invisible, receiving clients' positive feedback for their contributions to process implementation indirectly via their superiors. Interviewees asserted that such diluted recognition could not match direct accolades from clients. An Indian Senior Associate and Lawyer stated:

As a lawyer, you will be interacting with people. You meet the client to understand the problem, get familiar with him. This interaction is not there [in LPOs], you are just in front of the computer... In this interaction ... you get money ... [and] benefits but you are only reviewing, you are not drafting, you are not meeting the client. (Interview, April 22, 2012, Delhi)

In addition to LPO lawyers having to content themselves with the pleasure of vicarious, rather than actual client representation, instances of undisclosed client identities were reportedly considered irksome. Contrary to litigation where both lawyers' and clients' identities were known, ethical requirements of American law firms and business-related inter-organisational competition in offshoring meant maintaining client confidentiality in LPOs. Participants highlighted how, besides 
insisting that LPO vendors sign confidentiality clauses with their employees, clients themselves redacted sensitive material from documents prior to scanning and transmitting them.

\section{Experiencing Disillusionment}

Notwithstanding the attractive organisational ethos presented by LPOs, dissatisfaction was reported. Managerial rhetoric, a perceived inauthentic work culture and labour market contingencies were among the factors underlying disillusionment. Employees could "see through" their employer's claims of American organisational culture with participants highlighting the "doublespeak" pervading LPOs and providing illustrations of the discrepancies between espoused and actual managerial practices. Not only did organisational hierarchy retain its relevance in spite of the professed embrace of flatter structures but variance in stated and enacted work organisation and performance parameters was noted, including: first, despite the emphasis on fixed hours, LPO employees worked beyond stipulated hours, usually without receiving adequate compensation; and second, the alleged commitment to work-life balance was compromised through the requirement of team bonding activities that occurred on weekends as well as through presenteeism, which was rewarded over task-related criteria. As one employee commented,

The management has come up with a form which you need to sign if you want work-life balance. Once you sign the form you would not have to sit late but the next [pay] increment would be $30 \%$ less. I think that is quite odd, if you complete your work in stipulated hours, why do you need to sit late. This mentality ... makes the employee lethargic. Lots of employees in my company don't work in eight hours, they play, they go out for a smoke, they go out with a friend for lunch and then they sit back late. (Interview, Indian Lawyer and Associate, April 25, 2012, Delhi)

Inconsistencies in matters of recruitment and promotions were also described. Whereas objectivity, merit and transparency were cited as the benchmarks, in reality, personalised, identity-based and network-linked relationships where ingratiation and exchange prevail were major influences, disadvantaging employees on gender, caste, religion and region. Such dynamics evidence the persistence of the Indian workplace ethos (D'Cruz and Noronha 2012).

LPO lawyers, who habitually contrast the work culture in offshoring with litigation, alluded to its contrived nature. Their air-conditioned offices where job completion proceeded via ICTDs and involved interactions with corporate-groomed colleagues who spoke English cut them off from the "real" world of courts where task execution occurred through relationships with fellow lawyers, clients, assistants and friends. The collegiality integral to the legal profession takes a backseat in commoditised LPO work where there was no need for co-operative effort. Complicating the LPO lawyers' sense of disconnect with the ethos of their workplace were the issues of age and attrition. Fissures between young and old employees arose owing to both inter-generational differences leading to divergent world views and work experiences. Older lawyers not only considered "freshers" to be immature and more prone to sycophancy but also those with litigation backgrounds found the LPO work environment stifling. High 
turnover adversely affected employee relationships in LPOs and stood out as a departure from litigation where lawyers spent their professional lifetime together. Indeed, the "fun-and-games" agenda pursued by LPO HR managers, unheard of in litigation, was viewed as incapable of sparking off and cementing workplace bonds. An Indian lawyer explained:

My HR head is a young lady and she feels every week people should do some kind of jumping around, some treasure hunt... As managers we have excuses - we have lot of work. We will not say take our team. Sometimes I go and participate... I don't relate much with it. (Interview, Indian Lawyer and Operations Manager, January 3, 2010, Bengaluru)

Apart from instability, the complexity surrounding the employment contract in LPO evoked lawyers' disquiet. A manager stated:

In India, lawyers are cheap labour. A junior lawyer in litigation is paid about 5,000 or 6,000 rupees.... [W] hen you offer them 10,000, the very cheap labour is captured and you can make them work. You don't expect them to stay with you for long. They will serve for one or two years and go. Attrition is a common problem with every LPO, because of overwork. They go on churning their resource like anything..., extract the maximum in a limited time and earn [high] profits. That is the main motive of this whole business. (Interview, Indian Lawyer and Manager, April 25, 2012, Delhi)

That LPOs are merely glamourised work contexts whose impeccable exterior houses an undistinguished interior emerged during the 2008-2009 recession. Job insecurity was palpable and exposed managerial rhetoric in matters of employment, performance and retention. Whereas rationality, calibre and openness were always invoked as organisational standards, the recession evidenced the role of ingratiation in job continuity. Thus, irrespective of appraisal scores, those who had pleased their superiors kept their positions, while others became "performance casualties" forced to resign as evidenced elsewhere (see D’Cruz et al. 2014).

Undoubtedly, the most relevant factor responsible for participants' disillusionment was deskilling and deprofessionalisation. Losing their disciplinary expertise and social standing owing to the commoditised nature of offshoring tasks was a uniform experience across participants, leading many of them to reconsider their career trajectories. Switching to litigation or law firms where job design and work organisation capitalised on and enhanced their legal knowledge and skills was frequently mentioned. However, the LPO experience was considered irrelevant by litigators and law firms, meaning that transitioning lawyers had to start from scratch. Those willing to endure the challenges of competition, sycophancy, network-based functioning and poor remuneration were able to regain their competence and professional identities and establish successful traditional legal careers. Knowing the promise of this avenue, many lawyers who took up LPO employment after a stint in litigation always retained the possibility of returning. Maintaining the validity of their Bar Council licenses, instead of surrendering them as required by LPO firms, was common, followed by the simultaneous pursuit of court practice and LPO jobs. Moreover, the jobs that the corporate sector offered were few and not everyone got the opportunity to work on a contract management project in a LPO firm, the experience of which was valued in the corporate sector. Yet there were others who, finding the transition daunting owing to high entry barriers and meagre 
compensation, opted to stay with LPOs and explore career mobility there. Overall, the particularities of LPO employment did little to transform the entrenched social structure controlling the legal profession. A Senior Associate explained:

While practising in court we get 3,000 to 4,000 rupees per month, in spite of putting in 18 to 19 hours of work [per day]... . So the mirage called LPO appeals to you. People get some good perks but dig their own graves. You get third class work that is not legal in a strict sense. The situation is not as rosy as they present.... Actually, we are [going] nowhere.... We have aspirations to become lawyers, to be intellectuals, but the economic strain pushes us towards the LPO but LPO is nothing. (Interview, Indian Lawyer and Senior Associate, April 29, 2012, Delhi)

Interestingly, disillusionment did not catalyse lawyers to pursue collective action, for two broad reasons. First, organisational restraints and constraints were referred to. In terms of restraints, LPOs ensured that their employees signed non-unionisation clauses. Lawyers, despite their professional expertise which indicated to them their fundamental right to association and the illegality of such a clause, still acceded to it and never attempted to unionise due to fear of employer reprisal and job loss. In terms of constraints, LPOs ensured work organisation such that they afforded their employees neither the time to think about or organise collective action. Indeed, the absence of a sense of community, evidenced by a lack of sympathy for those laid off, served as an important impediment. Second, some participants also mentioned that white-collared professionals employed by progressive new economy organisations purporting to protect employee interests had no need for unions. They held that unions were for bluecollar workers and public sector employees whose organisations were discriminatory and inefficient and impinged on employee rights. Besides this, lawyers displayed little history of unionisation with participants either avoiding clashes with management or seeking new employment (see also Noronha and D'Cruz 2009b). Only a few LPO lawyers mentioned collective action confronting management that successfully reversed unacceptable decisions. They attributed their effectiveness to management's awareness that, as lawyers, they could effectively but inexpensively sue the organisation. In one case a participant explained:

If you have been working in the sector for five years, it will be like any other company culture. The only difference being the exploitation may not be that easy because lawyers rebels from inside. If somebody has practiced, they know the law. The other side [management] also is a little apprehensive in taking actions against lawyers. In X LPO firm they slashed the employees from 280 to 100 people.... There was a strike across the board saying "you put them on bench [retained without work] or provide them some kind of relief...." Before that there was no option. Thus, they were benched, "you will be given 75 percent of the salary." (Interview, Indian Lawyer and Manager, May 5, 2012, Delhi)

Thus, although our first theme identified the LPO management's efforts to create a client-savvy organisation with policies designed to attract and retain employees, our second theme highlights the unintended consequences of these policies, which through the process of work organisation systematically results in de-skilling, taking away the autonomy that is central to a lawyer's identity. Lawyers enter the profession with the belief that their control over the work is necessary given the nature of legal practice and therefore autonomy cannot be handed over to administrators. Thus, it is not surprising that lawyers shy away from the pressure of standardised work, performance 
measurement and advanced technology that devalue and commoditise the profession (Brooks 2011; Simon 2012). Lawyers in LPOs feel increasingly disillusioned working under this managerial regime. Although the focus on profit maximisation to the point of employee exploitation through work intensification was constantly referred to, it was the denial of professional respect through managerialism that hurt lawyers' pride.

LPO work, centring on document review presents a clear antithesis to the essence of the legal profession. A time intensive but mundane task, document review lent itself to division, standardisation, routinisation, objectification and measurement, allowing for the application of process-driven measures such as accuracy, efficiency and cost effectiveness. This high-volume and scalable work calls for minimal supervision and presents low legal and ethical risks. Thus, the majority of outsourced jobs comprise "commodity" legal work requiring only minimal firm-specific knowledge. Indeed, participants had to blindly follow client instructions, rather than exercising professional autonomy.

In these circumstances, the collegiality integral to the legal profession took a backseat. As a result, LPOs rely on money and prestige to entice law students and lawyers to join their organisations. Further, to induce performance and loyalty amongst lawyers, LPOs establish managerialist HR departments and design locations and furnishings that mimic their corporate clients. However, although rationality was always invoked as an organisational standard, ingratiation found its way into organisational functioning. It is important to reiterate that such dynamics evidence the persistence of the Indian workplace ethos.

\section{Conclusion}

This article examined the nature of offshoring in the Indian legal profession. It considered the debate as to whether the Indian legal profession is transformed and benefitted by offshoring or has seen commoditisation and deskilling. The study findings underscore that, although LPOs opened more career doors for lawyers who did not have adequate social capital for more traditional employment, the simplified, standardised and routinised nature of offshored work led to deprofessionalisation, reducing lawyers to "glorified clerks" engaging only a narrow subset of their legal skills. In fact, as outsourcing lawyers do not interact with clients and colleagues abroad, they are unable to build up their expertise to gain legal insights. Further, the degradation and deskilling of LPO lawyers renders them far less employable in the legal labour market meaning few exit options from LPOs are available. Thus, although LPOs enabled lawyers to detach themselves from the courts the role earlier envisaged for Indian lawyers as business advisers, negotiators or social planners did not fructify (see Galanter 1968). Nonetheless, given that even well-trained lawyers had little chance of succeeding at the bar without the requisite social capital, the corporate culture espoused by LPOs continues to be an attractive proposition for lawyers from non-elite backgrounds. In effect, LPO firms provided parallel avenues for career mobility but did not transform the traditional legal system or destabilise the local legal market which, at its core, remains socially networked. Lawyers working in LPOs continued to belong to an underclass of lawyers performing routine and mundane work. The commodification in LPOs deepened the 
stratification between the elite and rank and file both at the national and international level. This included the widening of existing gender stratification patterns. There was a danger of women getting ghettoised into deskilled and dead-end, routinised and poorly remunerated LPO work, while men occupy the more prestigious Indian litigation business.

What does this study mean for the rise of knowledge work? Management gurus and futurists have pointed to these occupations with high information and knowledge content, as replacing capital as the basis of social status and power. The informational networked society is deemed to be one in which manual labour is increasingly displaced by knowledge-rich employment (Bell 1973; Castells 2010; Drucker 1993). Key concepts describing knowledge work such as autonomy, responsibility, commitment, initiative, creativity, independent judgment, communicative skills, discretion and customer orientation derived from the world of professions and services are now considered the normative characteristics of work (Dankbaar, and Vissers 2009). Underlying this argument is the notion that the conditions of knowledge work are spreading to other categories of workers, whereas routine work is either being abolished, upgraded or marginalised (Thompson et al. 2001).

Interestingly, our work on Indian LPOs confirms the contrary. Jobs remain routine, with a substantial component of the apparent growth being accounted for by an increase in low-level information handling occupations (Fleming et al. 2004). Indeed, there is a revitalisation of "scientific management" contributing to a general deterioration of conditions in both manual and professional/managerial work (Crowley et al. 2010). This can be attributed to managers walking a tightrope between according workers autonomy and organisation profitability. Other market requirements such as productivity and efficiency also force managers to control workers and reduce their work autonomy (Dankbaar and Vissers 2009). In fact, various social and economic factors have been combining to make professional work more like other employment constricted in terms of job content, performance, autonomy, and ability to exercise professional discretion that once characterised professional status. Principles of scientific management, originally developed for application to manual labour, are being applied to white-collar work and to the professions through the medium of bureaucratisation and information technologies (Crain 2004).

Thus, our work highlights the contradictions in LPOs management of lawyers, in trying to create a corporate culture that seeks to entice lawyers to work in LPOs, but simultaneously espousing work routines that de-skill and de-professionalise the employees they hire. Until the quality of work in LPOs moves from the routine to more advanced legal work, the disillusionment experienced by Indian lawyers in LPOs will continue.

\section{Notes}

1. After transcription of the interviews, we then immersed ourselves in the data following the well-established procedures identified by Strauss and Corbin (1998). Further details with regard to the analysis and triangulation processes are available from the authors.

2. In April 2007, Indian recruitment and training firm Rainmaker introduced the GLP certification test designed in concurrence with three LPO companies, JuriMatrix, Bodhi 
Global, and Quislex. The first GLP was administered on September 162007 in New Delhi, Bombay, Pune, Bangalore and Hyderabad.

3. The partnership model is characterised by intimacy, informality, negotiation, compromise, consultation and collegiality. This model values professional knowledge, peer control, indivisible work responsibility and strong links with clients. In fact the partnership strategy emphasises aggregation of partners' individual interest rather than central planning or direction of client facing activities. Co-ordination of professional work is achieved by standardisation of inputs through training that creates appropriate skills and attitudes rather than through processes. Authority is widely distributed or decentralised amongst partners with a strong emphasis on consultation (Cooper et al. 1996; Pinnington \& Morris, 2003). Managed professional businesses emphasise formal planning methods, with detailed target setting and performance management systems. Since the primary aim of the firm is to provide effective and efficient business services in a globally integrated manner, control and co-ordination of work are placed in the hands of a dedicated managerial cadre and their routine driven systems that optimise profits and efficiency (see Cooper et al. 1996; Falconbridge and Mazio 2007; Greenwood and Hinings 1996; Muzio and Ackroyd 2005; Pinnington and Morris 2003).

\section{Disclosure statement}

No potential conflict of interest was reported by the authors.

\section{References}

Bachrach, J. 2008. "Offshore Legal Outsourcing and Risk Management: Proposing Prospective Limitation of Liability Agreements under Model Rule 1.8(h)." Georgetown Journal of Legal Ethics 21 (3): 631-654.

Ballakrishnen, S. 2009. "Where Did We Come From? Where Do We Go? An Enquiry into the Students and Systems of Legal Education in India." Journal of Commonwealth Law and Legal Education 7 (2): 133-154.

Ballakrishnen, S. 2013. "Why is Gender a Form of Diversity?: Rising Advantages for Women in Global Indian Law Firms.” Indiana Journal of Global Legal Studies 20 (2): 1261-1289.

Batt, R., V. Doellgast, H. Kwon, M. Nopany, P. Nopany, and A. da Costa. 2005. The Indian Call Centre Industry: National Benchmarking Report Strategy, HR Practices, \& Performance. Ithaca: Cornell University, School of Industrial and Labor Relations, Center for Advanced Human Resource Studies CAHRS Working Paper \#05-07.

Bell, D. 1973. The Coming of the Post-Industrial Age: A Venture in Social Forecasting. London: Heinemann.

Bierman, L., and M. Hitt. 2007. "Globalization of Legal Practice in the Internet Age." Indiana Journal of Global Legal Studies 14 (1): 28-34.

Brooks, R. 2011. Cheaper by the Hour: Temporary Lawyers and the Deprofessionalization of the Law. Philadelphia: Temple University Press.

Campbell, I., and S. Charlesworth. 2012. "Salaried Lawyers and Billable Hours: A New Perspective From The Sociology of Work." International Journal of the Legal Profession 19 (1): 89-122.

Castells, M. 2010. Rise of the Network Society. Oxford: Wiley Blackwell.

Chadee, D. and R. Raman. 2009. "International Outsourcing of Information Technology Services: Review and Future Directions." International Marketing Review 26 (4/5): 411-438.

Cooper, D., C. Hinings., R. Greenwood, and J. Brown. 1996. "Sedimentation and Transformation: The Case of Canadian Law Firms." Organization Studies 17: 623-647.

Crain, M. 2004. "The Transformation of the Professional Workforce." Chicago-Kent Law Review 79 (2): 543-616. 
Crowley, M., D. Tope, L. Chamberlain, and R. Hodson. 2010. "Neo-Taylorism at Work: Occupational Change in the Post-Fordist Era." Social Problems 57 (3): 421-447.

D'Allaird, L. 2007. "The Indian Lawyer: Legal Education in India and Protecting the Duty of Confidentiality While Outsourcing." The Professional Lawyer 18 (3): 1- 11.

D’Cruz, P., E. Noronha and D. Beale. 2014. 'The Workplace Bullying-Organizational Change Interface: Emerging Challenges for HRM.” International Journal of Human Resource Management, 26(10): 1434-1459.

D’Cruz, P., and E. Noronha. 2012. "High Commitment Management Practices Re-Examined: The Case of Indian Call Centres." Economic and Industrial Democracy. 33 (2), 185-205,

D’Angelo, C. A. 2008. "Overseas Legal Outsourcing and the American Legal Profession: Friend or "Flattener"?" Texas Wesleyan Law Review 14: 167-195.

Daly, M., and C. Silver. 2007. "Flattening the World of Legal Services? The Ethical and Liability Minefields of Offshoring Legal and Law-Related Services." Georgetown Journal of International Law 38: 401-447.

Dankbaar, B., and G. Vissers. 2009. Of Knowledge and Work. Köln: Max Planck Institute for the Study of Societies, Working Paper 09/16.

Destefano, M. 2012. "Nonlawyers Influencing Lawyers: Too Many Cooks in the Kitchen or Stone Soup?" Fordham Law Review 80 (6): 2791-2845.

Dezalay, Y., and B. Garth. 2004. "The Confrontation between the Big Five and Big Law: Turf Battles and Ethical Debates as Contests for Professional Credibility." Law and Social Inquiry 29 (3): 615-638.

Drucker, P. 1993. The Post-Capitalist Society. Oxford: Butterworth-Heinemann.

Faulconbridge, J., 2008. "Managing the Transnational Law Firm: A Relational Analysis of Professional Systems, Embedded Actors, and Time-Space-Sensitive Governance." Economic Geography, 84 (2): 185-210.

Faulconbridge, J., and D. Muzio. 2007. "Reinserting the Professional into the Study of Globalizing Professional Service Firms: The Case of Law." Global Networks 7 (3): 249-270.

Fischer, B. 2010. "Outsourcing Legal Services, In-Sourcing Ethical Issues: An Examination of the Ethical Considerations Arising from the Practice of Outsourcing Legal Services Abroad." Southwestern Journal of International Law 16 (2): 451-475.

Fleming, P., B. Harley, and G. Sewell. 2004. "A Little Knowledge is a Dangerous Thing: Getting Below the Surface of the Growth of Knowledge Work' in Australia." Work, Employment and Society 18 (4): $725-747$.

Flood, J. 2011. "From Ethics to Regulation: The Re-Organization and Re-Professionalization of Large Law Firms in the $21^{\text {st }}$ Century". Accessed February 20, 2016. file://C:/Users/pc1/ Downloads/SSRN-id1592324.pdf.

Galanter, M.1968. “The Study of the Indian Legal Profession.” Law and Social Review 3 (2): 201217.

Galanter, M. 1972. “The Aborted Restoration of 'Indigenous' Law in India." Comparative Studies in Society and History 14: 53-70.

Gandhi, J. 2004. Law's State and Society: Indian Context. Jaipur and New Delhi: Rawat Publications.

Greenwood, R., and C. Hinings. 1996. "Understanding Radical Organizational Change: Bringing Together the Old and the New Institutionalism." Academy of Management Review 21 (4): 1022-54.

Hall, R. 1985. "Professional/Management Relations: Imagery vs. Action." Human Resource Management 24 (2): 227-236.

Hanson, A. 2009. "Legal Process Outsourcing to India: So Hot Right Now!" SMU Law Review 62 (4): 1889-1914.

Harmon, A. 2008. "The Ethics of Legal Process Outsourcing - Is the Practice of Law A "Noble Profession," Or Is It Just Another Business?” Journal of Technology Law and Policy 13 (2): 41-83.

Hegde, S. 1988. "Lawyers and the Legal System in India: A Critique". In Readings in the Sociology of the Professionals, edited by S. Lal, K, Khanna, A. Chandani and U. Nahar, 344- 360. Delhi: Gian Publishing. 
Jayaram, N. 1988. "Colonial Legacy and Class Nature of the Legal Profession in India". In Readings in the Sociology of the Professionals, edited by S. Lal, K, Khanna, A. Chandani and U. Nahar, 361-379. Delhi: Gian Publishing.

Krishnan, J. 2007. "Outsourcing and the Globalizing Legal Profession." William and Mary Law Review 48: 2189-2214.

Krishnan, J. 2010. “Globetrotting Law Firms, ”Georgetown Journal of Legal Ethics 23 (1): 57-102.

Kuruvilla, S. and A. Ranganathan. 2008. "Economic Development Strategies and Mmacro- and Micro-Level Human Resource Policies: The Case of India's 'Outsourcing' Industry.” Industrial and Labor Relations Review 62(1),39-72.

Mendelsohn, O. 2005. The Indian Legal Profession, the Courts and Globalisation. Journal of South Asian Studies 28: 301-320.

Miller, B. 2008. "The Ethical Implications of Legal Outsourcing." Journal of the Legal Profession 32: $259-272$.

Moog, R. 2008. "The Study of Law and India's Society: The Galanter factor." Law and Contemporary Problems 71: 129-137.

Muzio, D., and S. Ackroyd. 2005. "On the Consequences of Defensive Professionalism: Recent Changes in the Legal Labour Process." Journal of Law and Society 32 (4), 615-642.

NASSCOM. 2011. Indian Knowledge Services Outsourcing Industry, New Delhi: NASSCOM.

NASSCOM. 2013. The IT-BPM Sector in India, New Delhi: NASSCOM.

NASSCOM. 2014. The IT-BPM Sector in India, New Delhi: NASSCOM.

Noronha. E and P. D'Cruz. 2009a. Employee Identity in Indian Call Centres: The Notion of Professionalism. New Delhi: Sage.

Noronha. E and P. D’Cruz. 2009b. "Engaging the Professional: Organising Call Centre Agents in India.” Industrial Relations Journal 40(3): 215-234.

Pinnington, A., and T. Morris. 2003. "Archetype Change in Professional Organisations: Survey Evidence from Large Law Firms.” British Journal of Management 14 (1): 85-99.

Prasad, A., and A. Mago. 2007. "Legal Process Outsourcing: A Guide to Important Considerations, Risk and Achieving Success". Accessed February 20, 2016. http://apps.amer icanbar.org/intlaw/spring2010/materials/Legal\%20Process\%20Outsourcing/Legal\%20Process\% 20Outsourcing.pdf.

Regan, M., and P. Heenan. 2010. "Supply Chains and Porous Boundaries: The Disaggregation of Legal Services.” Fordham Law Review 78 (5): 2137-2191.

Robertson, C. 2011. "Collaborative Model of Offshore Legal Outsourcing." Arizona State Law Journal 43 (1): 125-179.

Sako, M. 2009. "Global Strategies in the Legal Services Marketplace: Institutional Impacts on Value Chain Dynamics1”. Accessed February 19, 2016. http://www.sbs.ox.ac.uk/ideas-impact/ novakdrucecentre/research/working-papers/global-strategies-legal-services-marketplace-insti tutional-impacts-value-chain-dynamics.

Sako, M. 2010. Make-or-Buy Decisions in Legal Services: A Strategic Perspective. Accessed February 20, 2016. http://www.sbs.ox.ac.uk/sites/default/files/tile_image/sako-make-or-buyin-legal-services.pdf.

Sathe, S., S. Kunchur, and S. Kashikar. 1983. "Pune Bar: A Study in Sociology of the Profession." Indian Bar Review 10: 47-79.

Schmitthener, S. 1968. "A Sketch of the Development of the Legal Profession in India." Journal of Law and Society Association 3 (2/3): 337-382.

Schultz, C. 2010. "Legal Off Shoring: A Cost-Benefit Analysis." The Journal of Corporation Law 35 (3): 640-661.

Scott, W. 2008. "Lords of the Dance: Professionals as Institutional Agents." Organization Studies 29 (2): 219-238.

Segal-Horn, S., and A. Dean. 2007. "The Globalization of Law Firms: Managerial Issues." International Journal of Service Industry Management 18 (2): 206- 219.

Simon, W. 2012. "Where is the 'Quality Movement' in Law Practice?" Wisconsin Law Review 2: 387-406. 
Spar, D. 1997. "Lawyers Abroad: The Internationalization of Legal Practice." California Management Review 39 (3): 8-28.

Strauss. A. and J. Corbin. 1998. Basics of Qualitative Research Techniques and Procedures for Developing Grounded Theory. London: Sage.

Susskind, R. 2008. The End of Lawyers? Rethinking the Nature of Legal Services. Oxford: Oxford University Press.

Terry, L. 2008. "The Legal World is Flat: Globalization and its Effect on Lawyers Practicing in Non-Global Law Firms." Northwestern Journal of International Law and Business 28 (3): 527560.

Thompson, P., C. Warhurst, and G. Callaghan, 2001. "Ignorant Theory and Knowledgeable Workers: Interrogating the Connections between Knowledge, Skills and Services" Journal of Management Studies 38:7, 923-42.

Tuft, M. 2010. "Supervising Offshore Outsourcing of Legal Services in a Global Environment: ReExamining Current Ethical Standards.” Akron Law Review 43 (3): 821-841.

Woffinden, K. 2007. "Surfing the Next Wave of Outsourcing: The Ethics of Sending Domestic legal Work to Foreign Countries under New York City Opinion.” Brigham Young University Law Review 2: 483-529. 